Research Article

\title{
Study on Characteristics of the Vibration and Noise of High-Power Scroll Compressor
}

\author{
Chuang Wang $\left(\mathbb{D},{ }^{1}\right.$ Zhen Wang $\mathbb{D}^{1},{ }^{1}$ Weiguo Yan, ${ }^{2}$ Hongkun Li, ${ }^{3}$ and Chunli Yang ${ }^{2}$ \\ ${ }^{1}$ Institute of Noise and Vibration, Dalian University, Dalian 116000, China \\ ${ }^{2}$ Panasonic Appliances Compressor (Dalian) Co., Ltd, Dalian 116000, China \\ ${ }^{3}$ School of Mechanical Engineering, Dalian University of Technology, Dalian 116000, China \\ Correspondence should be addressed to Zhen Wang; wangzhen@dlu.edu.cn
}

Received 22 May 2021; Revised 28 July 2021; Accepted 12 August 2021; Published 9 September 2021

Academic Editor: Peter Múčka

Copyright (c) 2021 Chuang Wang et al. This is an open access article distributed under the Creative Commons Attribution License, which permits unrestricted use, distribution, and reproduction in any medium, provided the original work is properly cited.

\begin{abstract}
With the rapid development of a high-power scroll compressor (HSC), the dynamic performance of a scroll compressor has an important impact on the vibration and noise of the whole compressor. So, the dynamic characteristics and structural acoustic radiation characteristics of HSC under dynamic excitation are studied by simulation and experiment in this paper. Firstly, the dynamic simulation model of HSC is established to analyze the time-domain and frequency-domain characteristics of bearing excitation and upper support excitation. At the same time, the finite element models of housing, upper support, and lower support are constructed to analyze the transient dynamic response of housing under the excitation source. Based on the vibration displacement of the housing surface, the prediction model of the housing radiated noise is also established, and then the radiated noise of the housing surface and the noise spectrum of the standardized test points are analyzed. Finally, the accuracy of the prediction model is verified by acoustic experiments. The experimental results show that the vibration and radiation noise of the housing can be accurately predicted by reasonable modeling to calculate the gas force and approximate the actual gas load. The vibration of the housing coupling system is the main source of the vibration characteristics of the HSC. The conclusions of the study can provide a reference for the low noise design of the HSC.
\end{abstract}

\section{Introduction}

The scroll compressor is a kind of volumetric fluid machine with the characteristics of energy saving, high efficiency, and compactness. It is widely used in air conditioning, refrigerator, and other refrigeration equipment, which puts forward gradually to the high power [1]. Compared with other traditional compressors, HSC has its special structural characteristics [2]. Driven by eccentric crankshaft, the moving and static scroll teeth of the HSC mesh with each other, through which a closed area is formed to compress the gas. Under the working condition of the HSC, the pressure pulsation, unbalanced dynamic load, and various assembly errors at the time of suction and discharge will endow rich and complex dynamic excitation to the vibration and noise of HSC [3]. Therefore, it is increasingly important to study the vibration and noise of HSC.
For the vibration and noise characteristics of the compressor, researchers have carried out a lot of dynamic characteristics experiment. For example, Morishita [4] had established the dynamic model of the scroll compressor and studied the characteristics of radial gas force, tangential gas force, and axial gas force. Ishii et al. [5, 6] further analyzed the dynamic model of the scroll compressor. Kim et al. [7] reduced the force of the bearing system by adjusting the phase and weight of the balance weight to generate different inertial forces. Lee et al. [8] studied the vibration of the pipeline system of the compressor and found that the vibration of the pipeline system is the result of the joint action of mechanical force and fluid force. Morini et al. [9] developed an innovative DM calculation strategy and realized the application of RE/CFD combination method in real world scroll machine. Ye et al. [10] developed a semiactive control method of pressure. An additional valve to adjust the 
pressure change rate is used in the modulation chamber, which could greatly reduce the noise level.

At present, the research on scroll compressor mainly involves noise control, scroll profile design, vibration, and noise of some structures. However, there are few research studies on dynamic characteristics and vibration and noise mechanism of the scroll compressor. In this study, experimental analysis, multibody dynamics analysis, transient response analysis, acoustic simulation analysis, and experimental verification are applied to study the vibration and radiated noise of HSC.

The construction of the HSC multibody dynamic model is introduced in Section 2. While the accuracy of the model is ensured by experimental modal analysis in Section 2.2, the power transfer model of HSC is discussed in Section 3. In Section 3.1, the gas load characteristics and its approximate calculation are discussed, and then the gas force whose amplitude and phase change with rotation angle is introduced into the dynamic model. The dynamic simulation results and further verification of the model are introduced in detail in Section 3.2 and Section 3.3. The transient response of the dynamic coupling model is discussed in Section 4 . The sound radiation of the housing structure and the spectrum characteristics of the standardized measuring points are studied in Section 5. Finally, based on the acoustic experiment, the accuracy of the whole simulation system is verified, and the error source is analyzed in Section 6.

\section{Results and Discussion}

\subsection{Multibody Dynamic Model of HSC}

2.1.1. Structure and Power Topology of HSC. HSC is a kind of volumetric fluid machine, which is mainly composed of moving scroll, static scroll, cruciform ring, upper cover plate, upper support, crankshaft, stator sleeve, and lower support, as shown in Figure 1. The teeth of the two scroll plates are exactly the same. They are installed with $180^{\circ}$ and stagger a certain distance to realize the multipoint meshing between the scroll teeth, forming three pairs of conjugate meshing points. From outside to inside, they are the suction cavity, the compression cavity, and the exhaust cavity in turn. The eccentric crankshaft drives the moving scroll to revolve around the static scroll.

Analyzing the power transmission route of HSC is greatly significant for further understanding the power transmission and vibration and noise analysis of it [11], which can also provide a reference for subsequent TPA analysis. HSC is a closed metal structure, and all the dynamic excitation is ultimately transmitted to the housing, causing the vibration of the housing system [12]. The power transmission route is mainly divided into three parts. The first part is the upper support, which is also the most complex part of dynamic excitation and power transmission. The second part is the stator sleeve, where the dynamic excitation is mainly the countertorque of the motor. The third part is the lower support. The excitation is mainly transmitted from the crankshaft to the housing through the bearing and the lower support. The topological relationship details of power transfer are shown in Figure 2.
This picture shows the connection relationship and power transmission path between the parts of the scroll compressor.

2.2. Model Construction and Accuracy Verification. Due to the complexity of internal components in the HSC, it is very inefficient to obtain the natural frequency and modal shape only through the test, so the combination of experiment and simulation is used in this section to establish an accurate simulation model. First of all, the global characteristics of natural frequency and the convenient switching of scanning points of Polytec laser vibration meter are used to carry out multipoint test. By observing the frequency response function at different positions, the natural frequencies of components are determined. Combined with the test results, the simulation models are modified, and then the vibration modes are determined by using the simulation software. Finally, the natural frequencies and modal vibration modes of components are obtained. The experimental equipment is shown in Figure 3.

In order to reduce the workload of calculation, it is necessary to simplify the model properly. Firstly, based on the actual model of HSC, the components are simplified. Some local components that have little influence on the calculation results, such as chamfer, fillet, and thread structure, are ignored. The model file is imported into ANSYS Workbench to solve. The materials and properties of the components are displayed in Table 1.

The simulation model is modified by means of experimental modal analysis and mass calibration, and the simulation results of the adjusted model are consistent with the test results after many modifications. The test results, simulation results, and errors of some components are listed in Table 2.

2.3. Construction of Multibody Dynamics Model. Through the above model verification, the accuracy of the model is verified. The components are assembled according to the actual prototype. The interference is checked in Solidworks, and then the assembly is saved as a general format file [3]. The assembly is imported into ADAMS software, and the material properties are added to the model according to Table 1. To solve the dynamic model of the scroll compressor in ADAMS, it is necessary to add constraints reasonably according to the actual motion relationship and gas load combined with the gas force. The detailed constraint relationships among the components are shown in Figure 4.

\section{Simulation Analysis of the Power Transmission System}

3.1. Determination of Simulation Condition. The magnitude, direction, and action surface of gas force in each compression chamber of the compressor change with the crankshaft angle. They are too complex to measure the gas pressure [13]. Therefore, according to the special modeling environment of ADAMS, the gas force in the compression chamber should be appropriately simplified. The general 


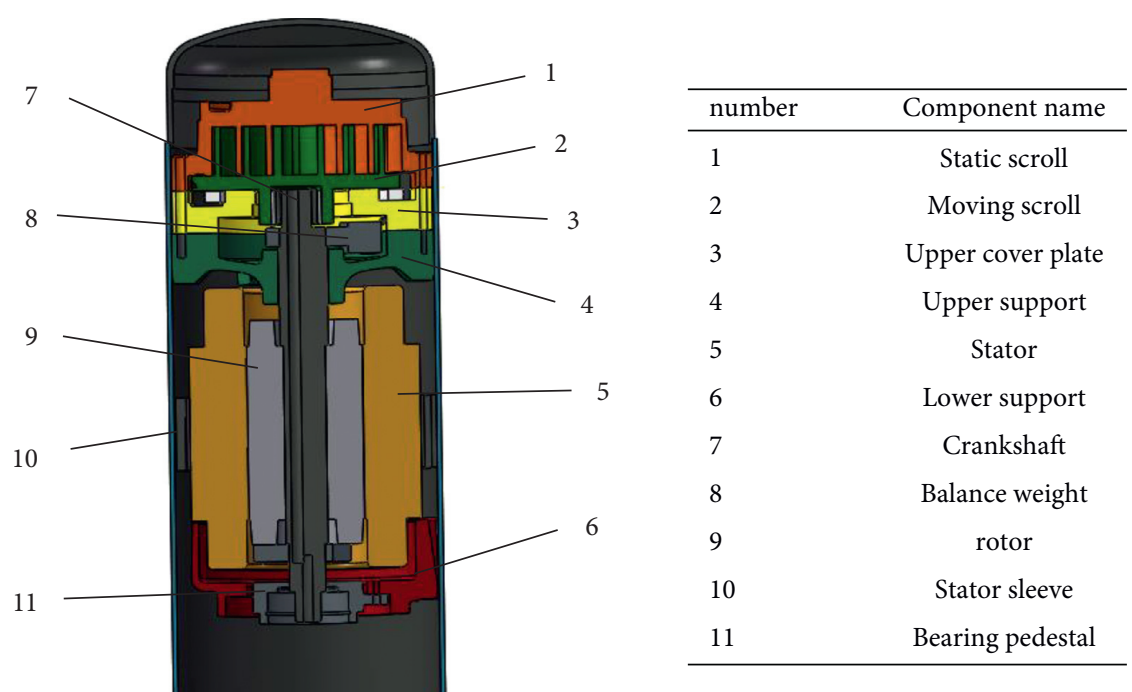

Figure 1: Assembly model of the HSC.

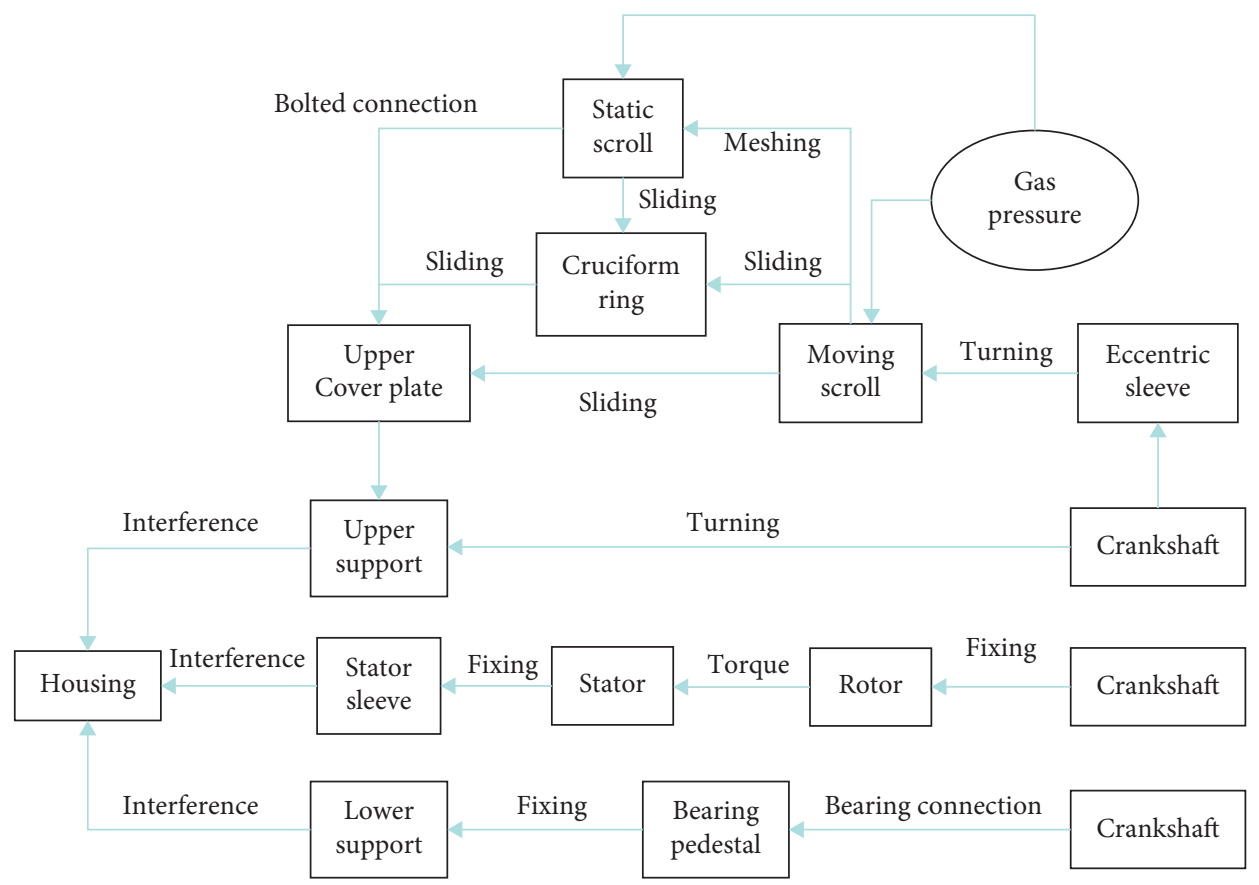

Figure 2: Dynamic topological model of the HSC.

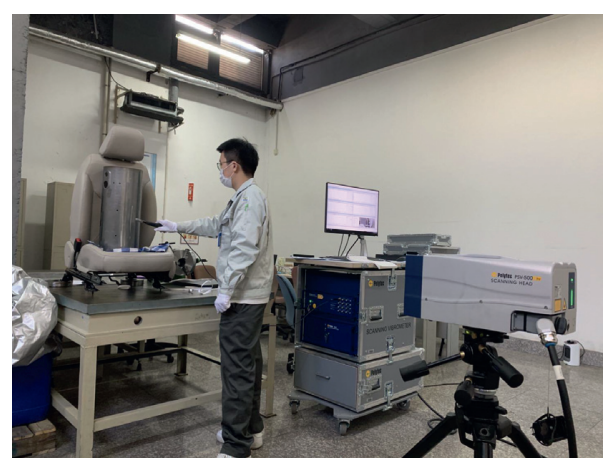

Figure 3: Experimental modal analysis. 
TABLE 1: Material properties of the scroll compressor.

\begin{tabular}{lcccc}
\hline Component & Material & Density $\left(\mathrm{Kg} / \mathrm{m}^{3}\right)$ & Elastic modulus $(\mathrm{Pa})$ & Poisson's ratio \\
\hline Moving scroll & HT350 & 7300 & $1.45 \mathrm{E} 11$ & $1.45 \mathrm{E} 11$ \\
Static scroll & HT350 & 7300 & $1.43 \mathrm{E} 11$ & 0.27 \\
Upper cover plate & HT300 & 7300 & $1.38 \mathrm{E} 11$ & 0.27 \\
Upper support & HT250 & 7280 & $2.12 \mathrm{E} 11$ & 0.27 \\
Housing & Q195 & 7690 & $7.2 \mathrm{E} 10$ & 0.156 \\
Cruciform ring & ADC12 & 2670 & $1.38 \mathrm{E} 11$ & 0.286 \\
Lower support & HT250 & 7280 & $2.07 \mathrm{E} 11$ & 0.33 \\
Crankshaft & 20Cr & 7830 & $138 \mathrm{E} 11$ & 0.156 \\
Bearing pedestal & HT250 & 7280 & & 0.156 \\
\hline
\end{tabular}

TABLE 2: Comparison of simulation results and experimental results.

\begin{tabular}{|c|c|c|c|c|}
\hline Model & Order & Test $(\mathrm{Hz})$ & Simulation $(\mathrm{Hz})$ & Mean error (\%) \\
\hline \multirow{6}{*}{ Upper support } & 1 & 859.25 & 890.4 & \multirow{6}{*}{1.8} \\
\hline & 2 & 1923.50 & 2002.6 & \\
\hline & 3 & 2560.25 & 2550.4 & \\
\hline & 4 & 3083.50 & 3085.2 & \\
\hline & 5 & 3182.25 & 3255.6 & \\
\hline & 6 & 4705.75 & 4720.2 & \\
\hline \multirow{6}{*}{ Lower support } & 1 & 779.75 & 748.93 & \multirow{6}{*}{5.4} \\
\hline & 2 & 1233.50 & 1172.6 & \\
\hline & 3 & 2070.00 & 1889.3 & \\
\hline & 4 & 2208.50 & 2027.2 & \\
\hline & 5 & 2400.50 & 2365.5 & \\
\hline & 6 & 2653.50 & 2508.3 & \\
\hline \multirow{6}{*}{ Moving scroll } & 1 & 1670.31 & 1708.7 & \multirow{6}{*}{1.9} \\
\hline & 2 & 1783.13 & 1778.7 & \\
\hline & 3 & 2364.38 & 2422.5 & \\
\hline & 4 & 2897.19 & 2976.0 & \\
\hline & 5 & 3381.88 & 3435.4 & \\
\hline & 6 & 3571.56 & 3644.1 & \\
\hline \multirow{6}{*}{ Static scroll } & 1 & 1365.94 & 1380.3 & \multirow{6}{*}{2.1} \\
\hline & 2 & 1742.81 & 1786.2 & \\
\hline & 3 & 2727.19 & 2651.3 & \\
\hline & 4 & 3009.38 & 2935.5 & \\
\hline & 5 & 3522.81 & 3518.4 & \\
\hline & 6 & 3864.06 & 3782.6 & \\
\hline \multirow{6}{*}{ Cruciform ring } & 1 & 799.75 & 764.4 & \multirow{6}{*}{2.7} \\
\hline & 2 & 1044.75 & 1019.3 & \\
\hline & 3 & 1273.50 & 1249.6 & \\
\hline & 4 & 1343.00 & 1337.3 & \\
\hline & 5 & 2198.50 & 2129.1 & \\
\hline & 6 & 2727.00 & 2626.5 & \\
\hline \multirow{6}{*}{ Upper cover plate } & 1 & 1229.50 & 1240.5 & \multirow{6}{*}{1.8} \\
\hline & 2 & 2090.25 & 2147.3 & \\
\hline & 3 & 3161.00 & 3177.1 & \\
\hline & 4 & 3372.25 & 3433.6 & \\
\hline & 5 & 3642.00 & 3746.2 & \\
\hline & 6 & 3752.00 & 3821.4 & \\
\hline \multirow{6}{*}{ Crankshaft } & 1 & 1353.50 & 1334.6 & \multirow{6}{*}{1.2} \\
\hline & 2 & 1407.00 & 1388.4 & \\
\hline & 3 & 3449.25 & 3404.3 & \\
\hline & 4 & 3554.50 & 3508.0 & \\
\hline & 5 & 4270.50 & 4284.0 & \\
\hline & 6 & 6009.25 & 6097.2 & \\
\hline
\end{tabular}



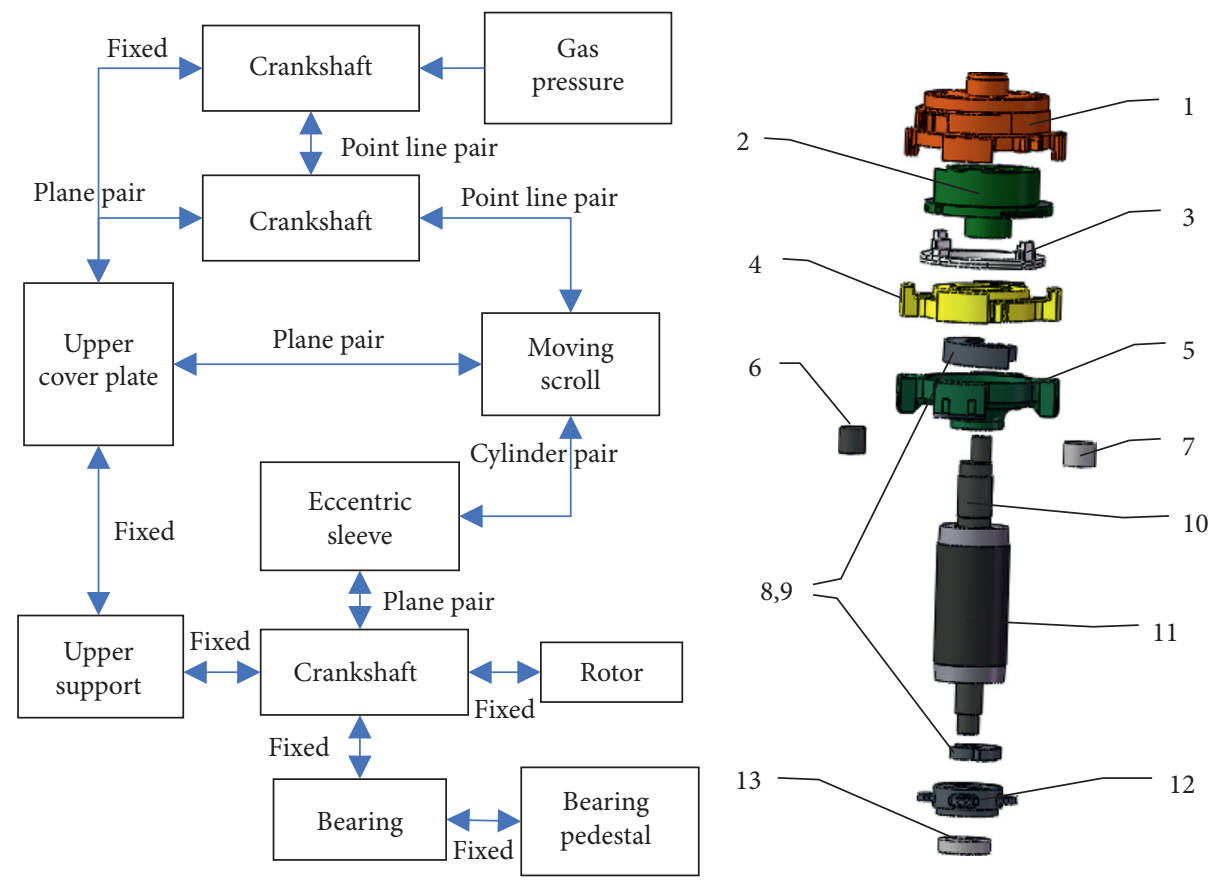

FIGURE 4: Constraint relationship of the scroll compressor component. (1) Static scroll. (2) Moving scroll. (3) Cruciform ring. (4) Upper cover plate. (5) Upper support. (6) Eccentric sleeve. (7) copper sleeve. (8,9) Balance weight. (10) Crankshaft. (11) Rotor. (12) Bearing pedestal. (13) Bearing.

process is as follows: firstly, the gas load is calculated in steps of $1^{\circ}$ in a complete cycle of $\left[0,360^{\circ}\right]$ by using Excel and then imported into ADAMS. The discrete points are interpolated and linearly extrapolated by using the spline function AKISPL. The gas load obtained is shown in Figure 5, and Figure 5(a) shows the gas force on the moving scroll and Figure 5(b) shows the gas force on the static scroll. When the crankshaft angle reaches about 220 degrees in this figure, there is an obvious sudden change in tangential force and axial force. Because the connection between the compression chamber and the exhaust chamber will cause the pressure of the compression chamber to rise suddenly (the pressure in the compression chamber is lower than that in the exhaust chamber), the transition from the compression chamber to the exhaust chamber is the reason for this phenomenon.

In the process of the HSC compressing the refrigerant, the size and direction of the gas load change with the rotation of the crankshaft [14]. Combined with the characteristics of the compressor gas load, the function embedded in ADAMS is used to realize the periodic load. Partial main function codes are as follows.

3.2. Verification of Simulation Model. In this section, the ADAMS simulation model established above is verified by kinematics theory, and the simulation results are verified by theoretical analysis of cruciform ring. As shown in Figure 6, in the $Y$ direction, the cruciform ring is matched with the corresponding key sliding fit of the static scroll through a pair of keyways $\mathrm{A}$ and $\mathrm{B}$. In the $X$ direction, it is matched with the key sliding fit of the moving scroll through a pair of keys $\mathrm{C}$ and $\mathrm{D}$. In this way, the translational motion of the moving scroll relative to the static scroll is realized.

It is pointed out in the paper [15] that when the center of the base circle of the moving scroll rotates around the center of the base circle of the static scroll, the displacement expression of the cruciform ring relative to the static scroll is as follows:

$$
\begin{aligned}
S_{y} & =-r \sin \theta \\
& =-r \sin (\omega t) .
\end{aligned}
$$

The displacement expression of the moving scroll relative to the cruciform ring is as follows:

$$
\begin{aligned}
S_{x} & =r \cos \theta \\
& =r \cos (\omega t) .
\end{aligned}
$$

The velocity and acceleration of the cruciform ring relative to the static scroll can be further calculated by equation (1):

$$
\begin{aligned}
V_{y} & =\frac{d_{S_{y}}}{d_{t}} \\
& =-\omega r \cos (\omega t) \\
& =-\omega S_{x}, \\
a_{y} & =\frac{d_{S_{y}}^{2}}{d_{t}} \\
& =\omega^{2} r \sin (\omega t) \\
& =\omega^{2} S_{y} .
\end{aligned}
$$




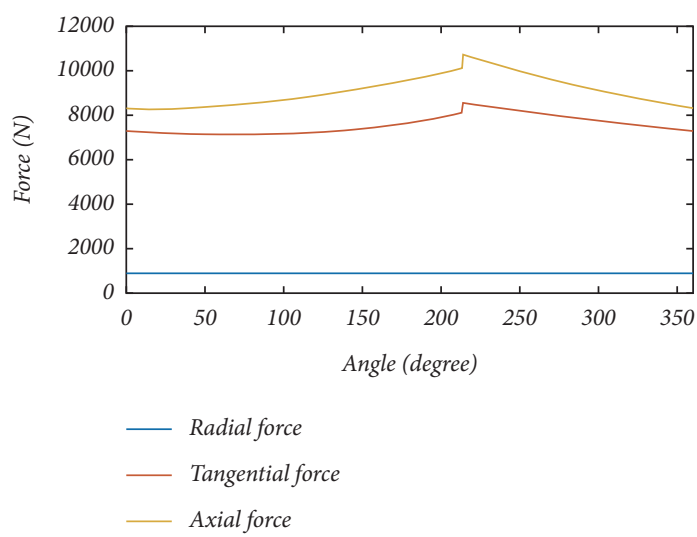

(a)

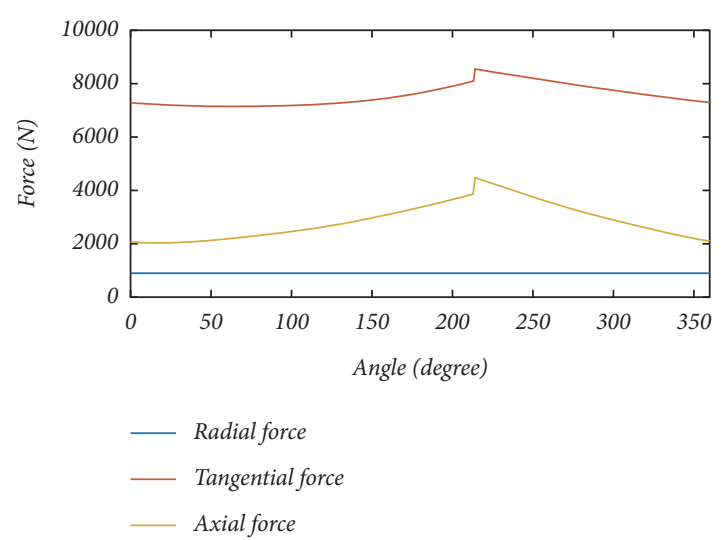

(b)

FIgUre 5: Gas load of the HSC. (a) Moving scroll. (b) Static scroll.

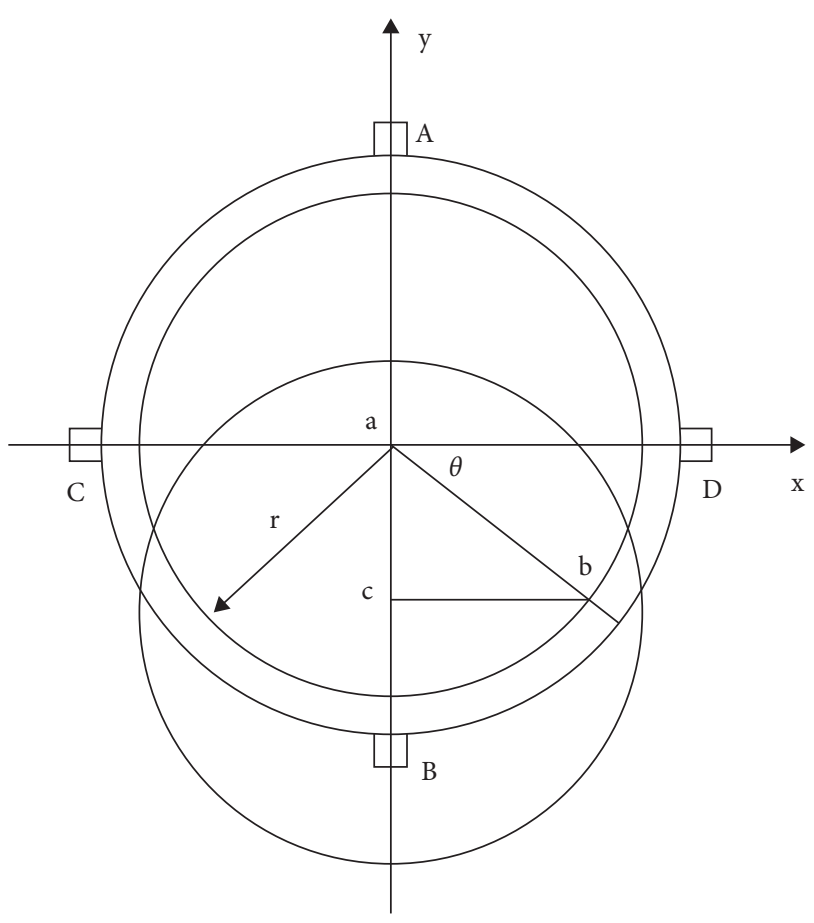

Figure 6: Simplified motion diagram of the cruciform ring.

It can be seen from the above formula that the displacement and acceleration of the cruciform ring are sinusoidal and cosine, respectively. The peak displacement is the same, but the phase is opposite. The simulation curves of displacement and acceleration of cruciform ring are shown in Figure 7. The simulation results are consistent with the theoretical results, so the simulation model is reasonable.

3.3. Dynamic Simulation and Analysis. The closed position of the suction chamber is selected as the initial position of the simulation, and then the gas force load and gravity load are added to the model [16]. The simulation steps are set to 5000 load steps. The crankshaft speed is set to $3000 \mathrm{rpm}$, and the simulation time is $0.1 \mathrm{~s}$.

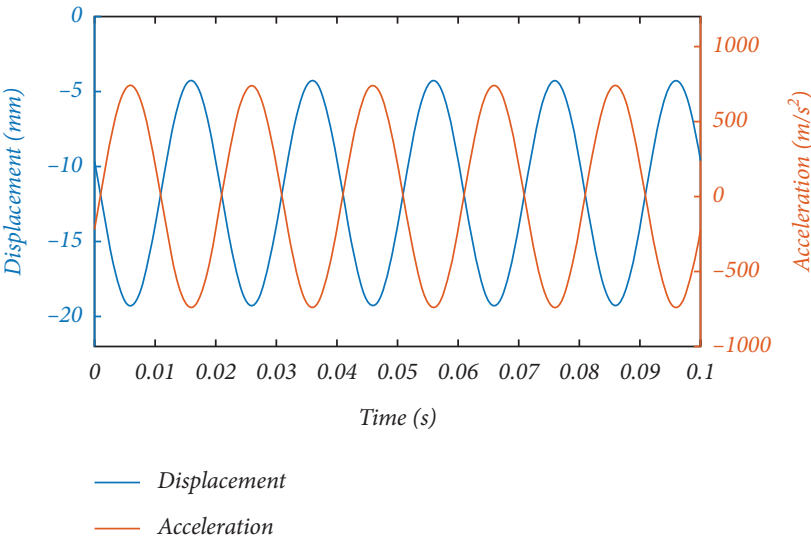

Figure 7: Displacement and acceleration curve of cruciform ring.

3.3.1. Force Analysis of the Cruciform Ring. When the HSC operates, the moving scroll moves parallel to the static scroll [17]. The cruciform ring plays an important role. The force of the cruciform ring is shown in Figure 8. Figure 8(a) shows the force of the static scroll and the cruciform ring at the two key matching points. It can be seen from the figure that the force at the two key matching points is the same, but the direction is opposite, which is in line with the actual operation state of the scroll compressor. Figure 8(b) shows the force acting on the moving scroll and cruciform ring at the two key points. The force is in a stable state in the second cycle of operation. Compared with Figure 8(a), there is a certain phase difference, and the force peak value is also different. The reason for the difference between the two figures is that the moving scroll not only slides relative to the cruciform ring but also moves around the static scroll. Combined with the results of the two figures, the rotation torque can be estimated, and the detailed analysis and demonstration will be demonstrated in the following works.

3.3.2. Results of Multibody Dynamic Analysis. The HSC has the function of automatic compensation, which can be realized by using eccentric sleeve [18]. It is mainly used to 


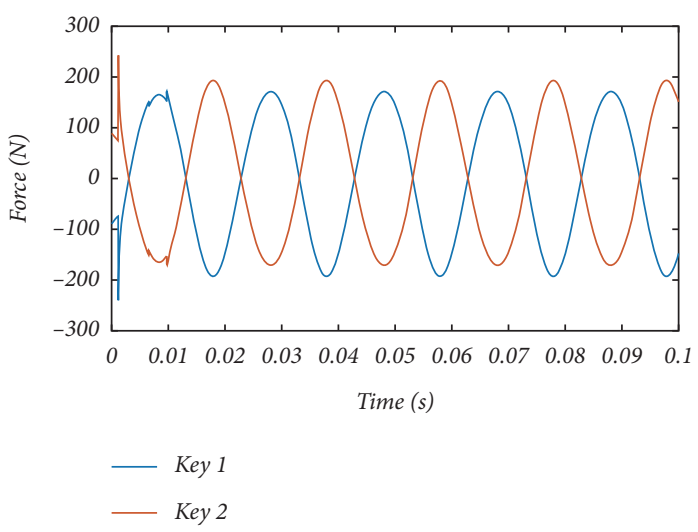

(a)

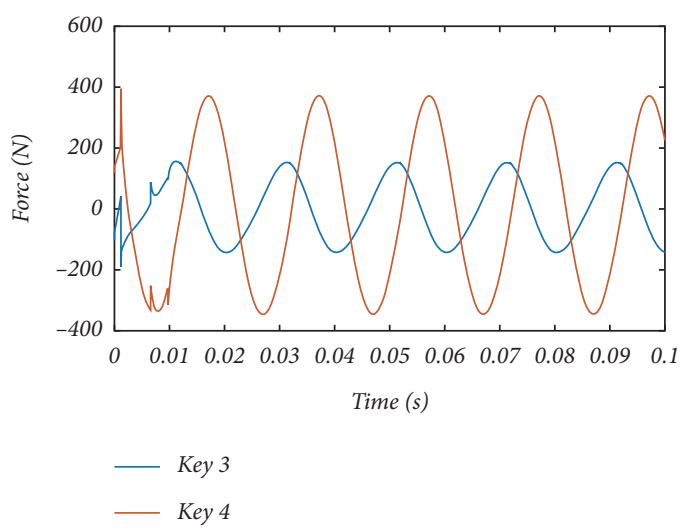

(b)

FIgURE 8: Force of the cruciform ring.

eliminate the abnormal operation and even damage the scroll plate caused by processing, operation wear, and magazine intervention in the compression process [19]. Therefore, the stress analysis of eccentric sleeve and crankshaft is also very important. The IMPACT function built in ADAMS is used to simulate the contact state. Figure 9 shows the simulation results of the contact force between crankshaft and eccentric sleeve. It can be seen from the figure that the contact force tends to be stable after the second simulation cycle.

Figure 10(a) shows the time-domain and frequencydomain curves of the bearing force. From the time-domain curve, its peak value appears near $115^{\circ}$, which is relatively stable, but the pressure suddenly changes around $216^{\circ}$. In combination with the above gas excitation curves, it can be found that the sudden change here is caused by the pressure fluctuation at the exhaust moment. On the spectrum diagram, the excitation frequency of bearing is mainly rotation frequency and its frequency multiplication. The above results further verify the accuracy of the simulation results.

Figure 10(b) shows the time-domain and frequencydomain curves of the upper brace stress. From the timedomain curve, the upper support force is about 7 times than that of the bearing. The force curve fluctuates more severely, peaking at $120^{\circ}$ and $270^{\circ}$. As with the bearing force, the force curve also changes abruptly around $216^{\circ}$. On the spectrum, the excitation frequency of the upper support is mainly twice than the rotation frequency.

The forces in Figure 10(a) and 10(b) can be decomposed into the component forces in $X, Y$, and $Z$ directions. $X$ and $Y$ directions refer to the radial direction of the bearing and the upper support, and the $Z$ direction refers to the axial direction of the bearing and the upper support. Figure 10(c) and Figure 10(d) show the force components of bearing and upper support, respectively.

\section{Transient Response Analysis of the Housing Coupling System}

4.1. Finite Element Model of Coupling System. The model is simplified and imported into ANSYS Workbench for model

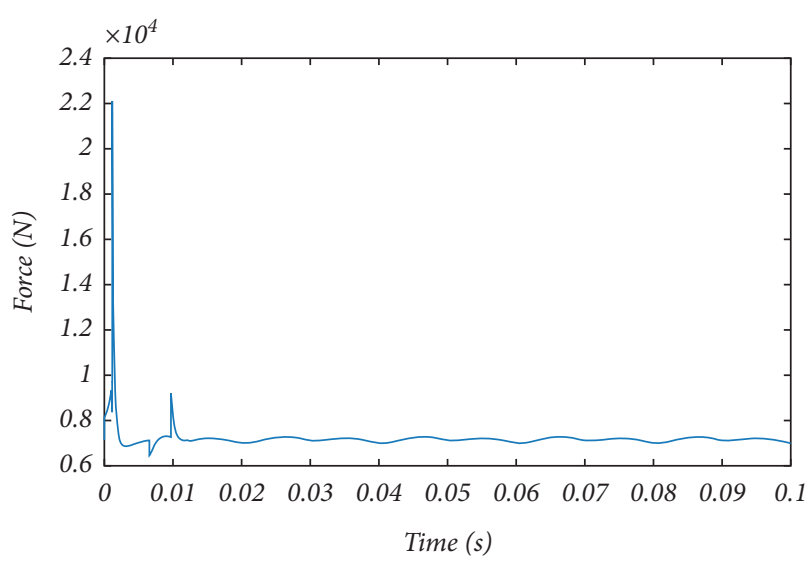

Figure 9: Contact force of eccentric sleeve.

preprocessing. The bearing load and upper support load are applied, and the calculation step is $1^{\circ}$ in a rotation cycle [20]. The upper support, stator sleeve, and lower support are directly bonded with the shell by binding contact. The bolt holes of the shell base are fixed with the ground. In order to obtain more accurate calculation results, the second-order tetrahedral mesh is adopted for the finite element model. The global mesh size is set to $5 \mathrm{~mm}$, and an adaptive mesh size algorithm is carried out for the mesh, including 1096826 nodes and 677725 elements. The processed model is shown in Figure 11.

4.2. Transient Response Analysis of the Housing Coupling System. The displacement response, velocity response, and acceleration response are shown in Figures 12(a)-12(c) in turn. Due to fixed constraints, parts with large vibration displacement and velocity are concentrated in the upper cover plate. The maximum vibration acceleration is located at the upper support and the lower support, and the distribution is relatively scattered. In view of this kind of vibration phenomenon, we must pay attention to two kinds of situations in the design process. First, referring to Figures 1 and 2, it can be found that the upper half of the scroll 

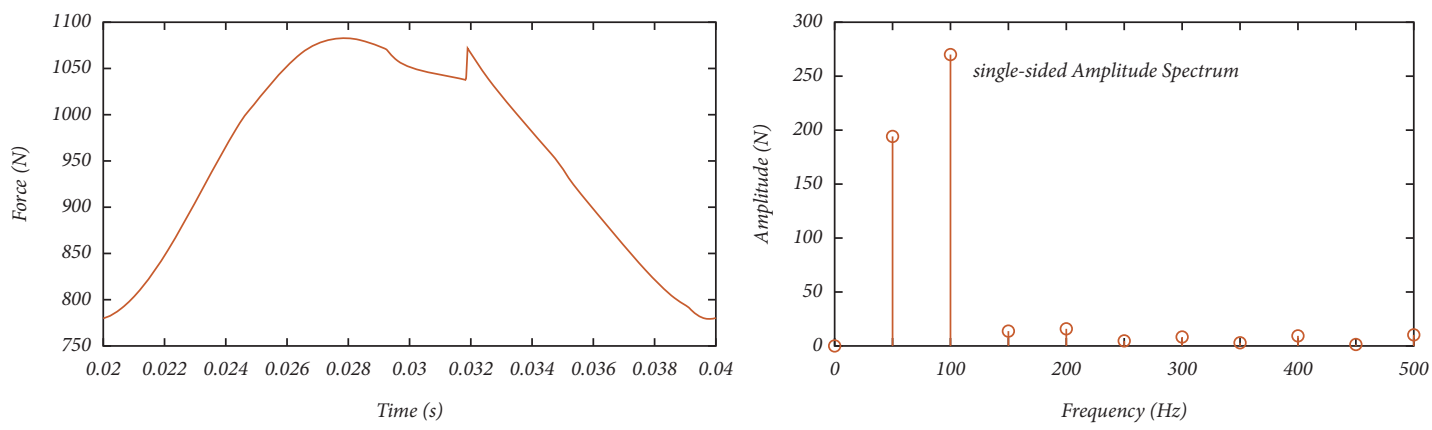

(a)
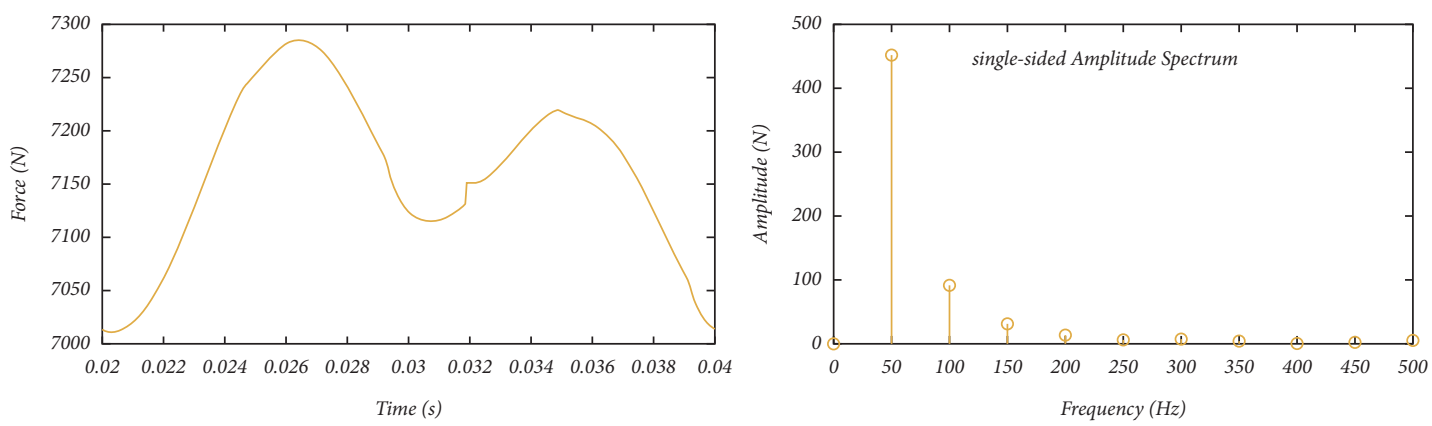

(b)
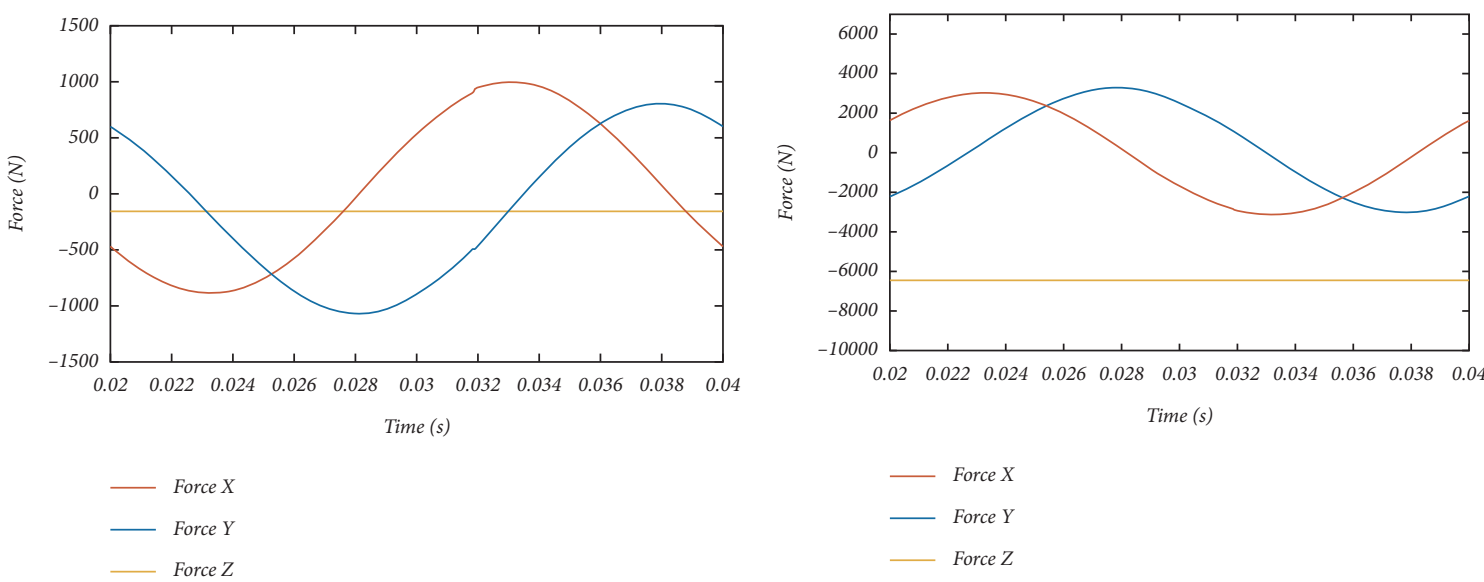

(c)

(d)

Figure 10: Time-domain and frequency-domain diagrams of main components.

compressor has a relatively complex structure, and the upper half of the upper compressor is not directly fixed, so it is easy to cause large vibration. In addition, there is pressure discontinuity during gas suction and exhaust in the upper part, which needs to be paid enough attention by designers. Because the pressure discontinuity often excites a wide excitation frequency band, the moving scroll and static scroll should be reasonably designed to reduce the pressure discontinuity caused by the closure of the suction chamber. Similarly, enough attention should be paid to the pressure discontinuity during exhaust. Second, from the simulation results of vibration, it can be seen that there is large vibration acceleration at the upper support and lower support. These two parts will transmit the vibration directly to the housing, resulting in radiated noise, so it is necessary to avoid resonance between these two parts.

\section{Simulation and Analysis of Housing Noise Radiation}

5.1. Acoustic Boundary Element Model of the Scroll Compressor. The vibration displacement response of the housing is taken as the boundary condition of noise prediction. Due to the small finite element size of the structure, it will greatly increase the calculation amount to directly use the finite element surface mesh as acoustic mesh [21]. The acoustic boundary element mesh is obtained by enveloping the vibration analysis finite element mesh, in which the size of the boundary element mesh is determined by the highest analysis frequency. Finally, the vibration boundary conditions are mapped to the boundary element mesh for noise prediction. According to the wavelength corresponding to the maximum effective analysis frequency is greater than or 


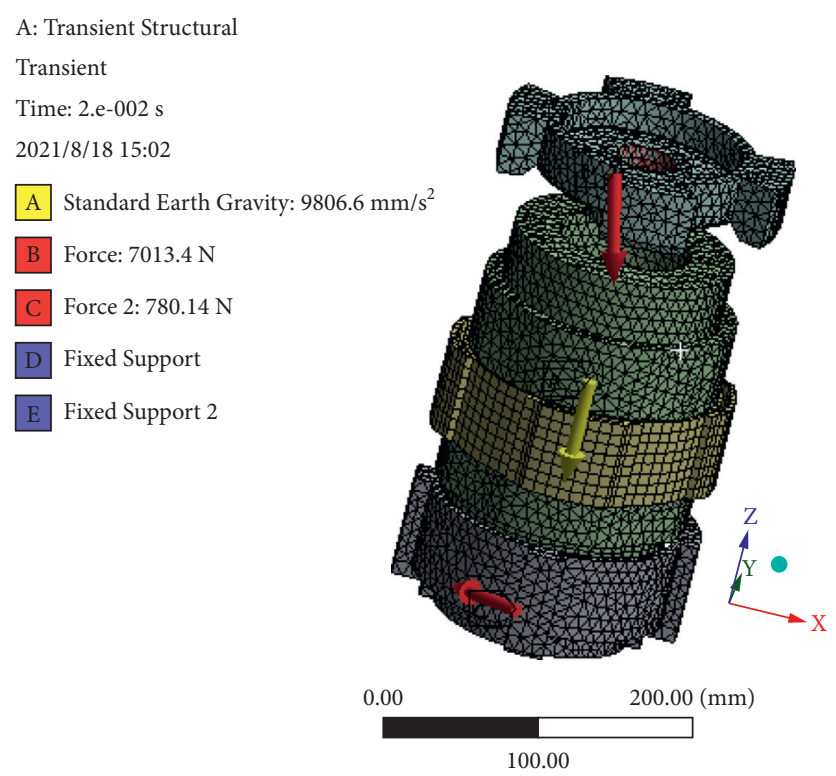

FIGURE 11: Finite element model of power system.

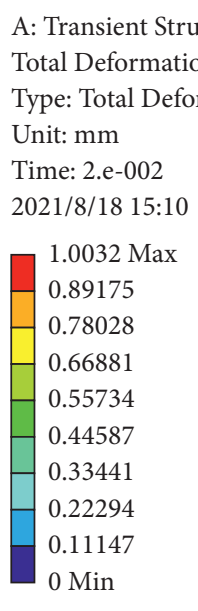

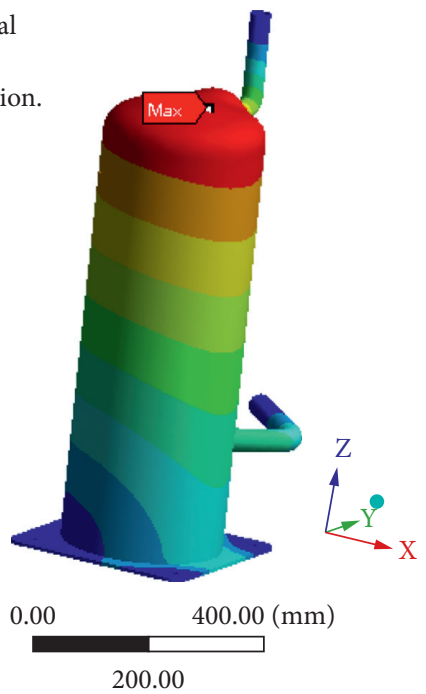

(a)
A: Transient Structural Total Velocity 2 Type: Total Velocity Unit: $\mathrm{mm} / \mathrm{s}$

Time: 2.e-002

2021/8/18 15:12

\begin{tabular}{|l}
$230.21 \mathrm{Max}$ \\
204.63 \\
179.05 \\
153.47 \\
127.89 \\
102.31 \\
76.735 \\
51.157 \\
25.578 \\
0 Min
\end{tabular}

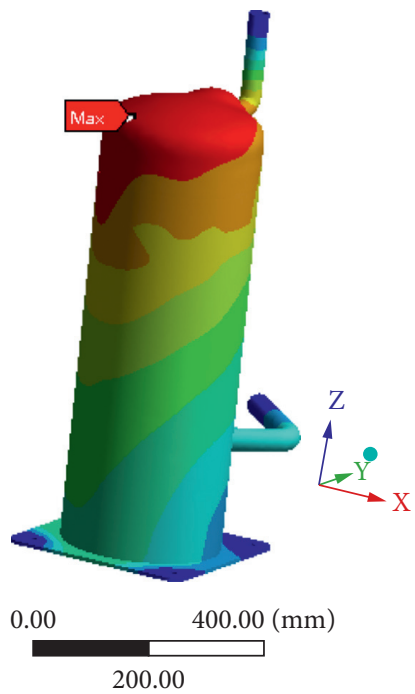

(b)

FIgURE 12: Continued. 


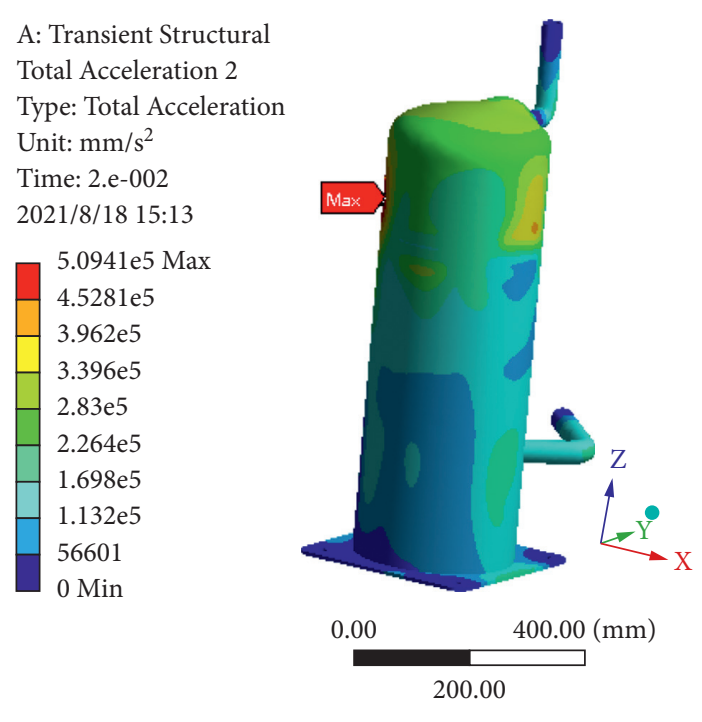

(c)

Figure 12: Transient dynamic response of housing.

equal to 6 times of the acoustic grid, and the acoustic grid size is determined [22]. The equation is shown as follows:

$$
L \leq \frac{C_{0}}{N \times F_{\max }},
$$

Where $C_{0}=340 \mathrm{~m} / \mathrm{s}, N=6$, and $F_{\max }$ is the highest analysis frequency, which is set as $4000 \mathrm{~Hz}$.

In order to ensure the accuracy of solving the frequency range, the final element size is $10 \mathrm{~mm}$. The boundary element model of the housing is shown in Figure 13.

5.2. Analysis of Acoustic Simulation. In software LMS Virtual.Lab, the air density is $1.225 \mathrm{~kg} / \mathrm{m}^{3}$, and the sound velocity is $340 \mathrm{~m} / \mathrm{s}$. Firstly, the vibration data of the structural grid are transmitted to the acoustic grid [23]. The effective analysis frequency is calculated by (4), and the calculation results are shown in Table 3 . The spectrum of sound power radiated from the housing surface is shown in Figure 14. Furthermore, a field point model is established at a distance of $1 \mathrm{~m}$ from the compressor. Figure 15 shows the sound pressure distribution at the peak frequency. In the low frequency band, the distribution of sound field is relatively uniform and has certain symmetry. In contrast, the distribution of sound field has obvious local characteristics in the high frequency band, and location with high noise radiation is concentrated in the middle of the housing. If it is necessary to reduce the radiated noise, the sound absorption treatment can be carried out in the middle of the housing.

5.3. Sound Spectrum Analysis of Measuring Points. According to the standard of scroll compressor noise test, the radiated noise level of the prototype is measured at a distance of $1 \mathrm{~m}$ from the welding point on the housing surface. According to the noise test standard required by Panasonic, the simulation test position is determined. The specific position is shown in Figure 16. Figure 17(a) illustrates the sound pressure level at 12 measuring points. It can be seen from the diagram that the peak value of sound pressure level is concentrated at $700 \mathrm{~Hz}$ and $1600-3000 \mathrm{~Hz}$. Each measuring point has similar spectral characteristics, and the sound pressure level is the highest at $1650 \mathrm{~Hz}$ and lower at high frequency after $3000 \mathrm{~Hz}$. Therefore, it can be found that the noise of this series of scroll compressors is mainly concentrated in the low frequency band and has obvious spectral characteristics.

Furthermore, points 1, 4, 7, and 10 near the upper support are selected for detailed spectrum analysis, as shown in Figure 17(b)-17(e). It can be seen from the figure that the sound pressure has obvious frequency domain characteristics, and the peak frequency is around $1650 \mathrm{~Hz}$ and $2200 \mathrm{~Hz}$, and the four measuring points have good frequency consistency. According to the conclusion of reference [24], there is a strong correlation between surface structure acoustic radiation and structure vibration of the scroll compressor. It is found that the peak frequency at $1650 \mathrm{~Hz}$ is close to the second natural frequency of the upper support, and the peak frequency at $2200 \mathrm{~Hz}$ is close to the third natural frequency of the upper support. Combined with the second and third mode shapes of the upper support, as shown in Figure 18, it is preliminarily determined that the structural sound pressure at the corresponding frequency is abnormal due to the first-order bending resonance of the upper support.

\section{Experimental Verification of the Simulation Model}

6.1. Experimental Test and Results. In order to ensure the accuracy of the noise test, the test site is a full anechoic room, and the test method adopts Panasonic test standard. The test equipment is 4189 microphone made by BK company of 


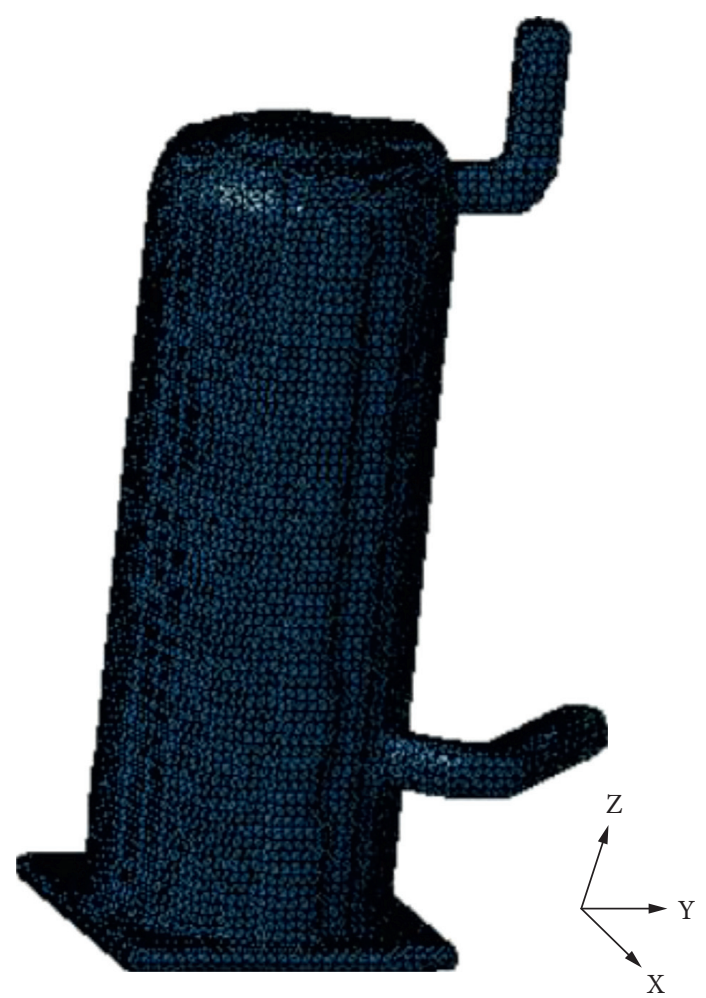

FIGURE 13: Boundary element model of the housing system.

TABle 3: Maximum effective calculation frequency.

Max frequency $(\mathrm{Hz})$

Effective rate (\%)

3026.8 100

3752.4

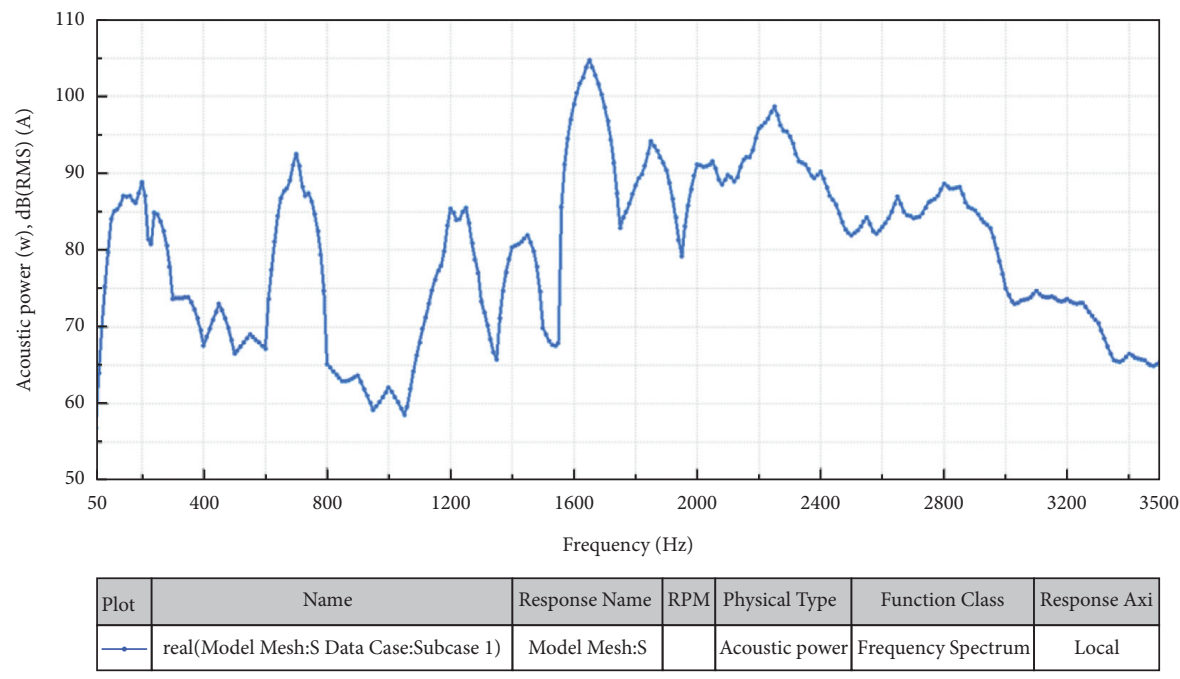

Figure 14: Radiated sound power spectra of housing. 

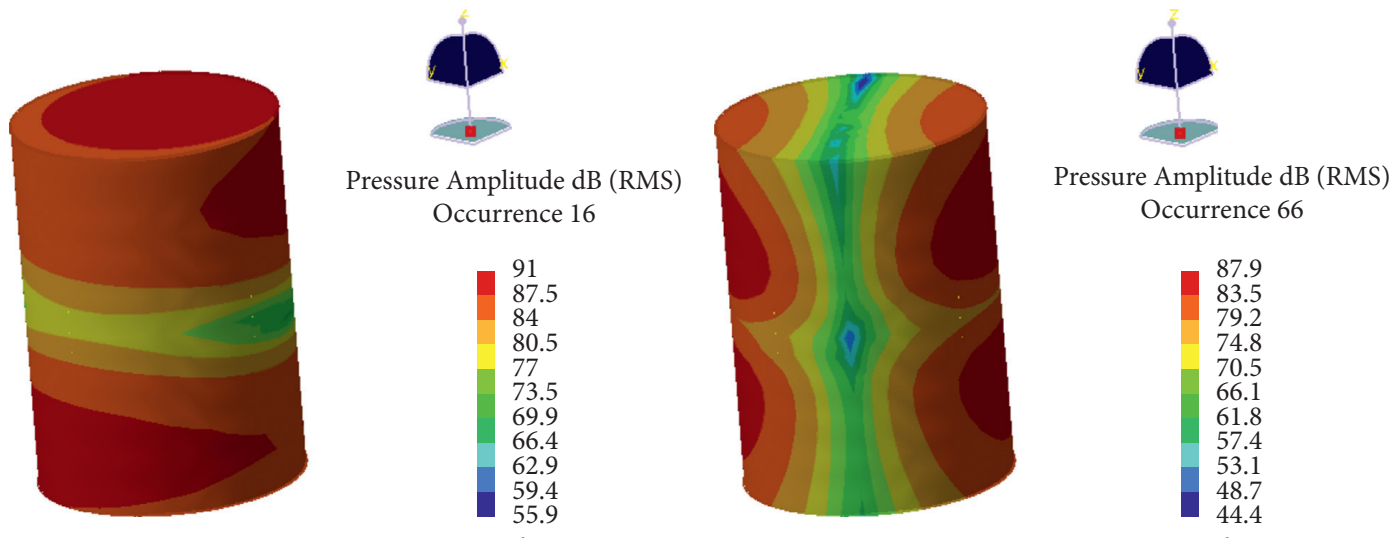

On Boundary
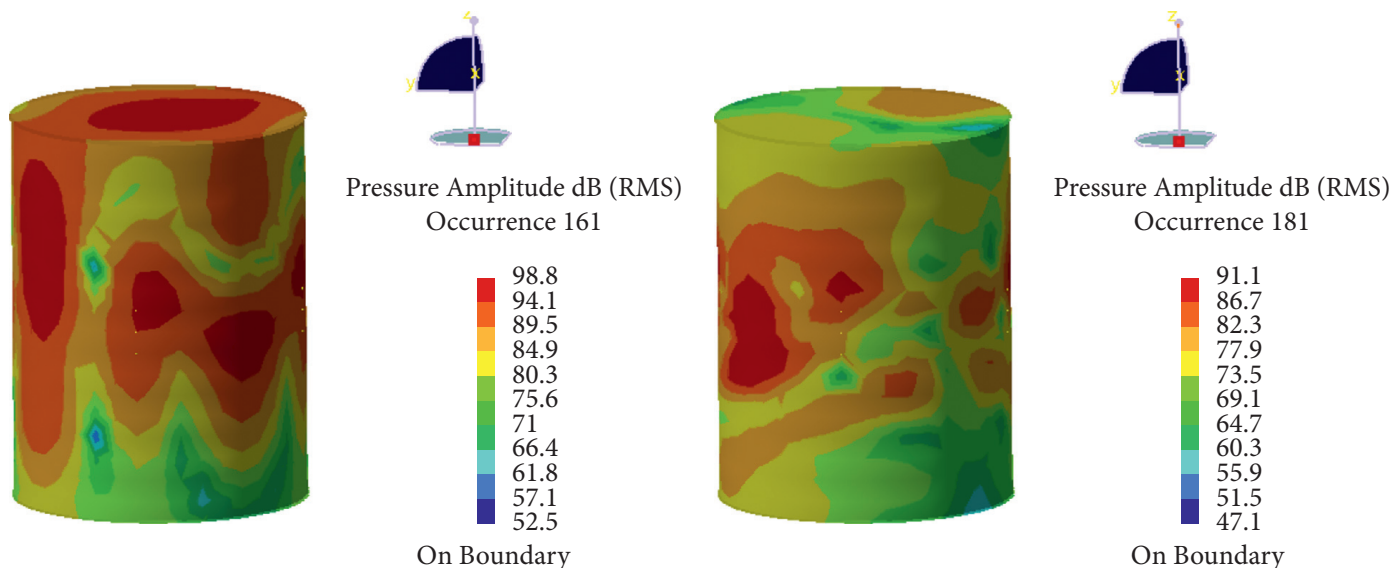

Pressure Amplitude dB (RMS) Occurrence 181
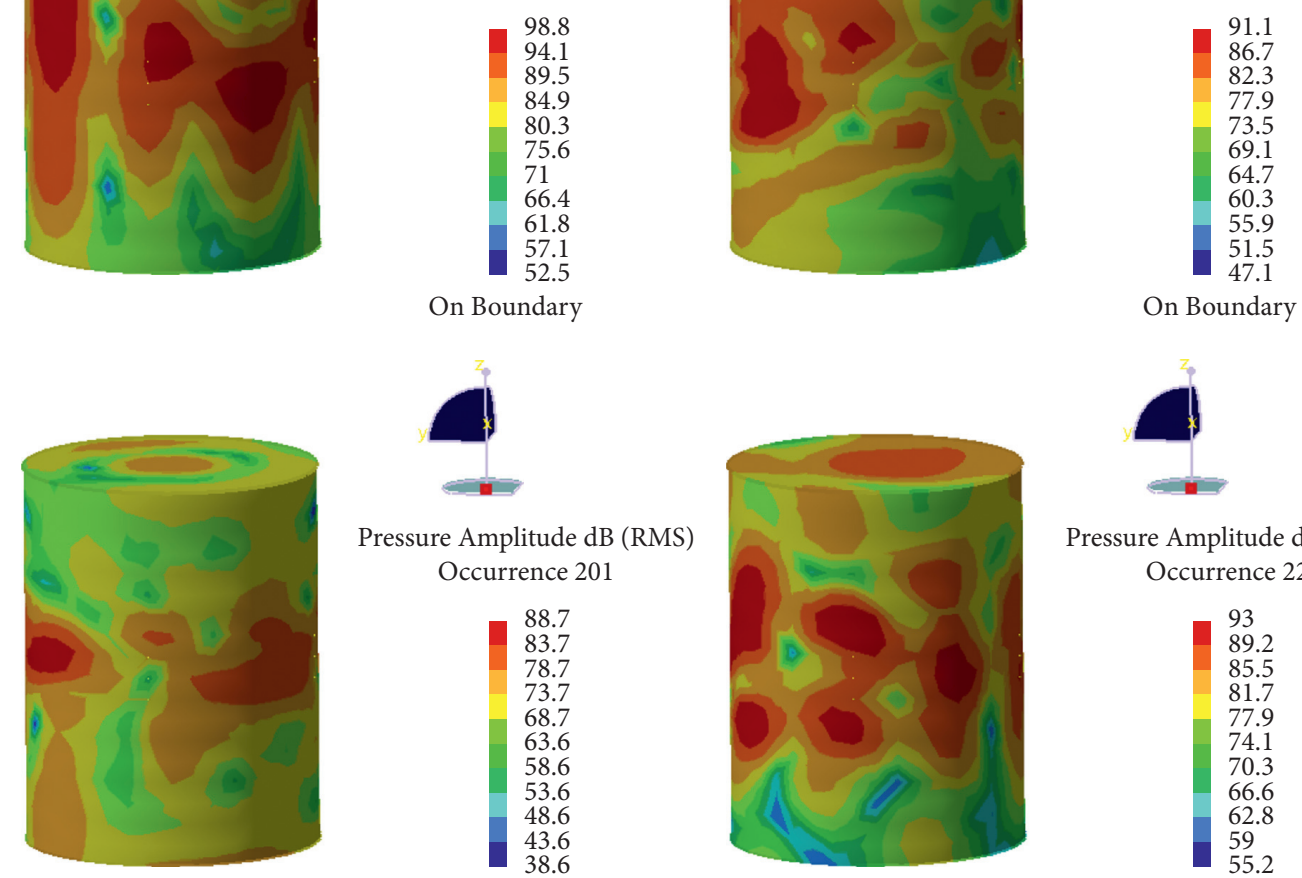

Pressure Amplitude dB (RMS) Occurrence 201

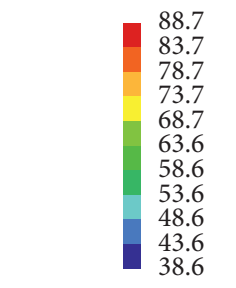

On Boundary

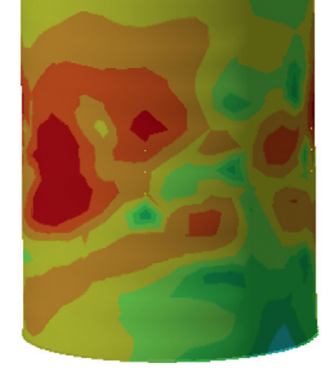

On Boundary

FIGURE 15: Sound pressure distribution at peak frequency.

Denmark, equipped with a amplifier, and the acquisition device is BK3560c multichannel data acquisition instrument. The device is connected to a computer for noise data acquisition. The experimental equipment is shown in Figure 19.

Under the stable operating condition of the HSC, sound pressure data of 4 measuring points of the housing are collected, and each point is collected for $10 \mathrm{~s}$. The acquired time-domain data are transformed into corresponding spectrum data by fast Fourier transform. The time and frequency domains of the measuring points are shown in Figure 20.

It can be seen that the main frequency band of the measured noise is in the low frequency range (below $3000 \mathrm{~Hz}$ ), which is consistent with the simulation results. The frequency spectrum has obvious frequency distribution characteristics and mainly concentrated in the range of $1600 \mathrm{~Hz}-2000 \mathrm{~Hz}$, which is highly consistent with the simulation results. Combined with the analysis results, it can be found that the vibration coupling system which is 

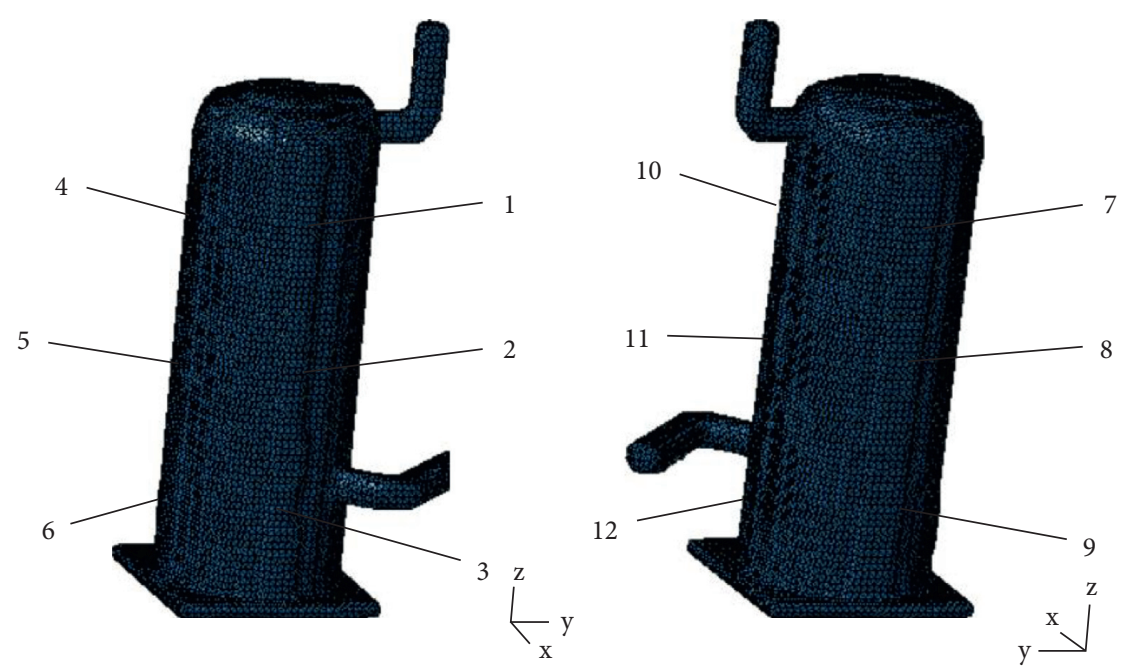

FIGURE 16: Location of the sound pressure measuring point.

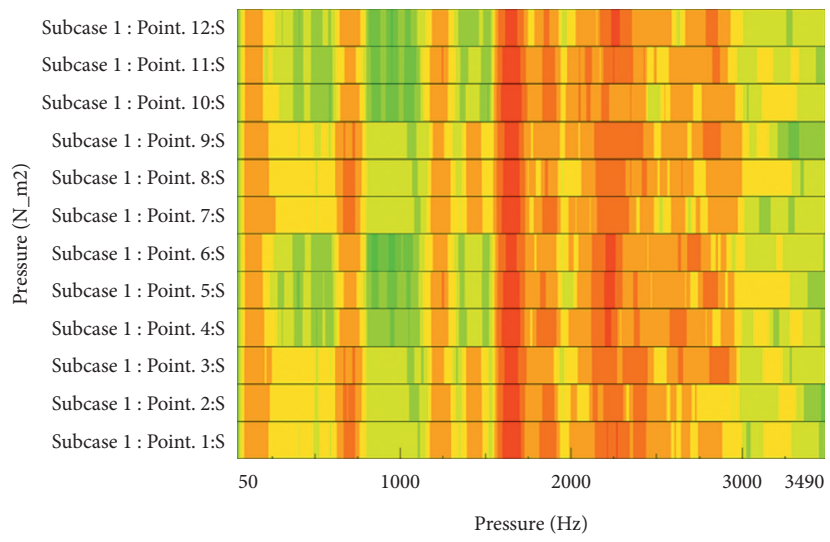

(a)

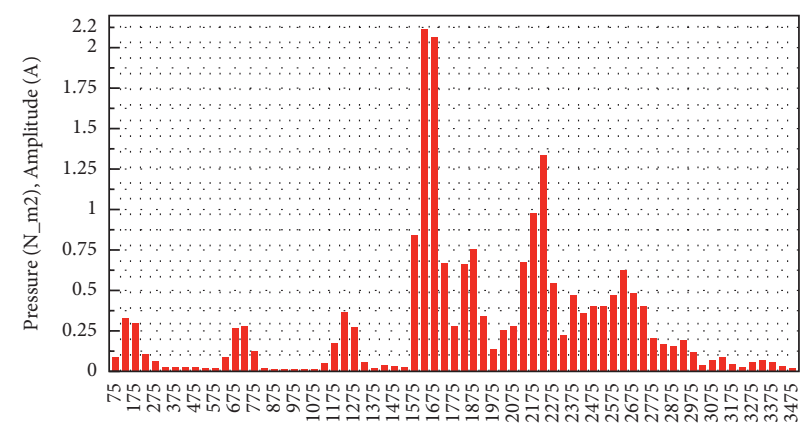

(c)

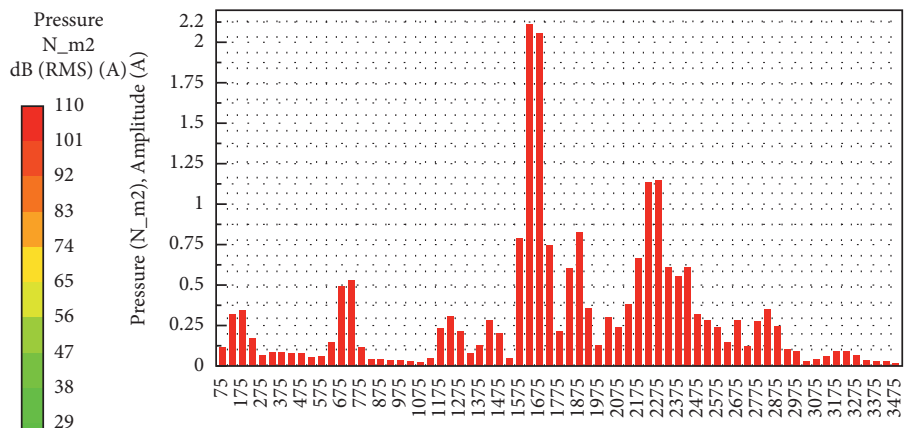

(b)

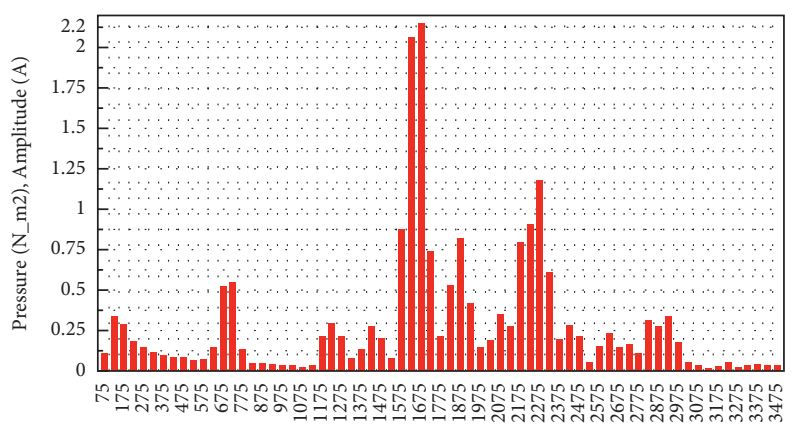

(d)

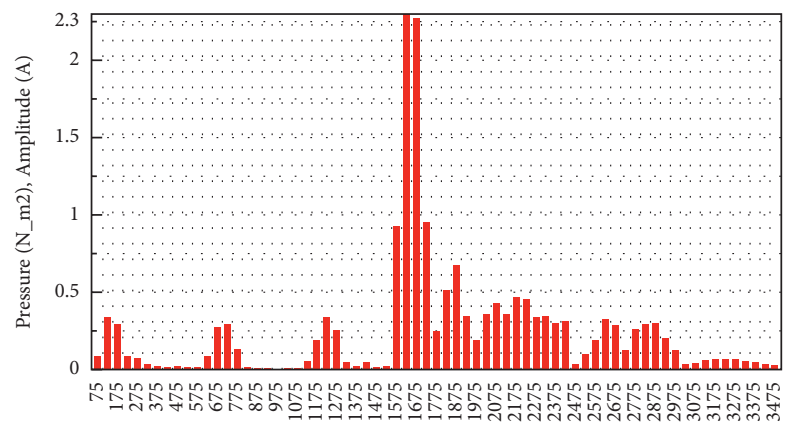

(e)

Figure 17: (a) Sound pressure level of 12 measuring points. (b) Point 1. (c) Point 4. (d) Point 7. (e) Point 10. 
I: Modal

Total Deformation 8

Type: Total Deformation

Frequency: $1656.5 \mathrm{~Hz}$

Unit: $\mathrm{mm}$

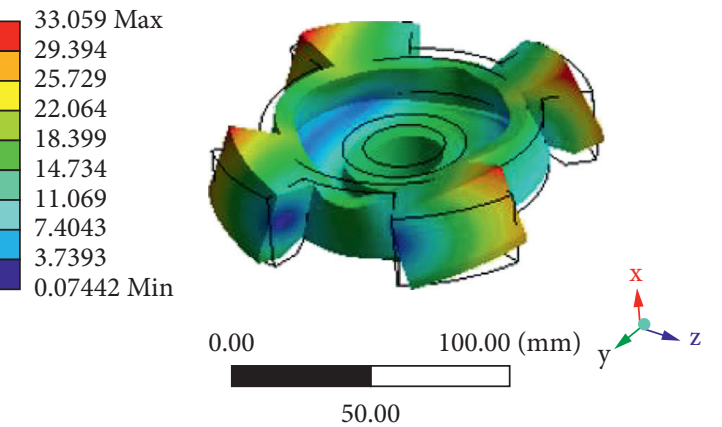

I: Modal

Total Deformation 9

Type: Total Deformation

Frequency: $2202.5 \mathrm{~Hz}$

Unit: $\mathrm{mm}$

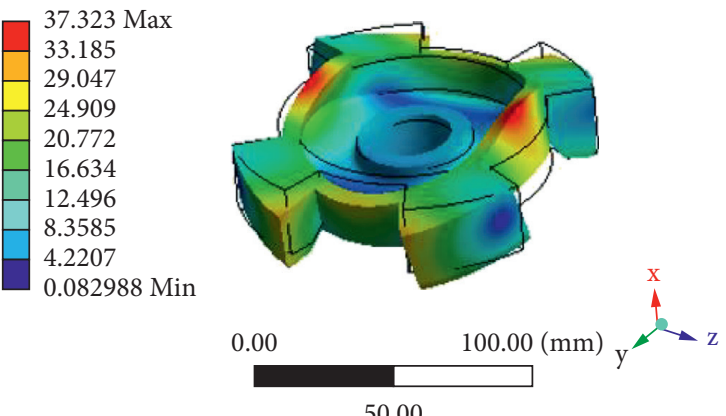

Figure 18: Modal shape of upper support.

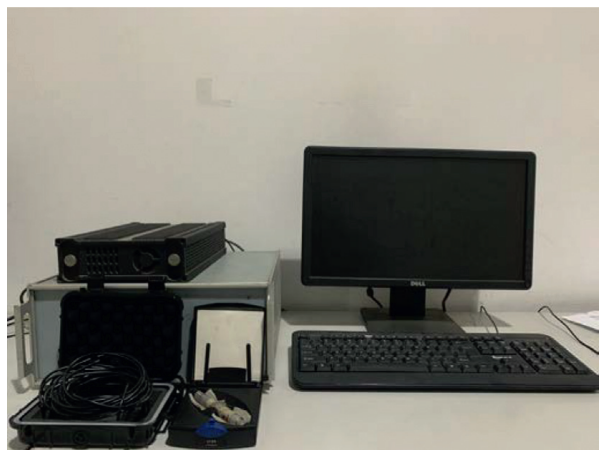

FIGURE 19: Experimental equipment.
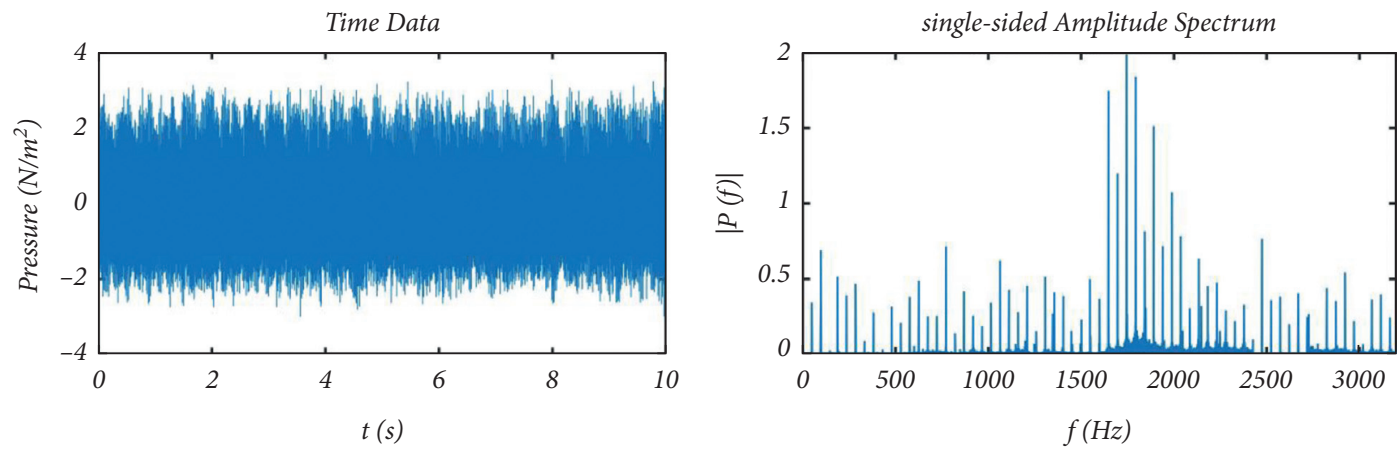

(a)
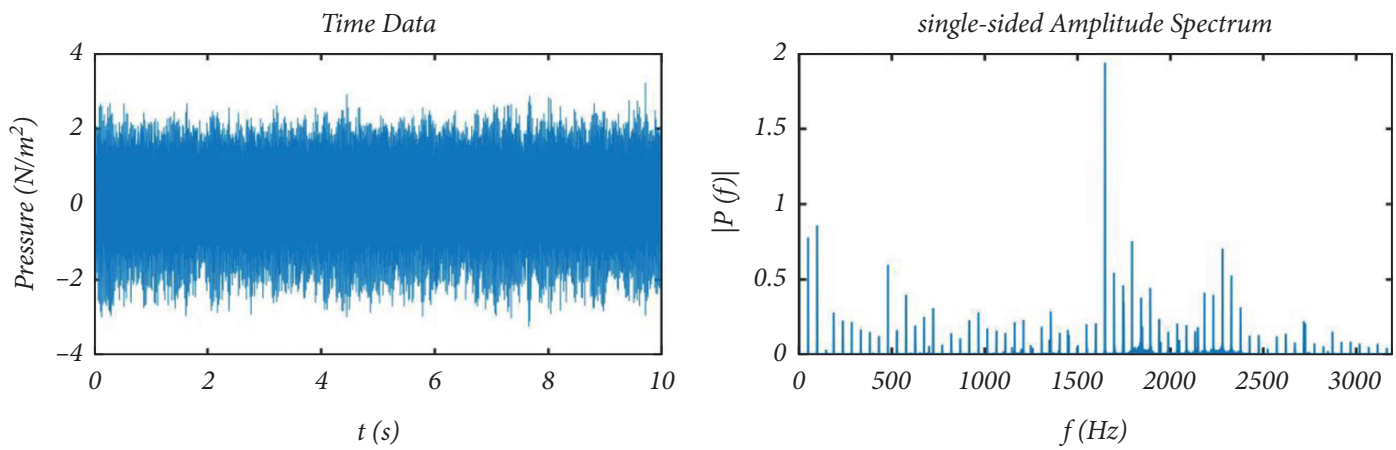

(b)

Figure 20: Continued. 

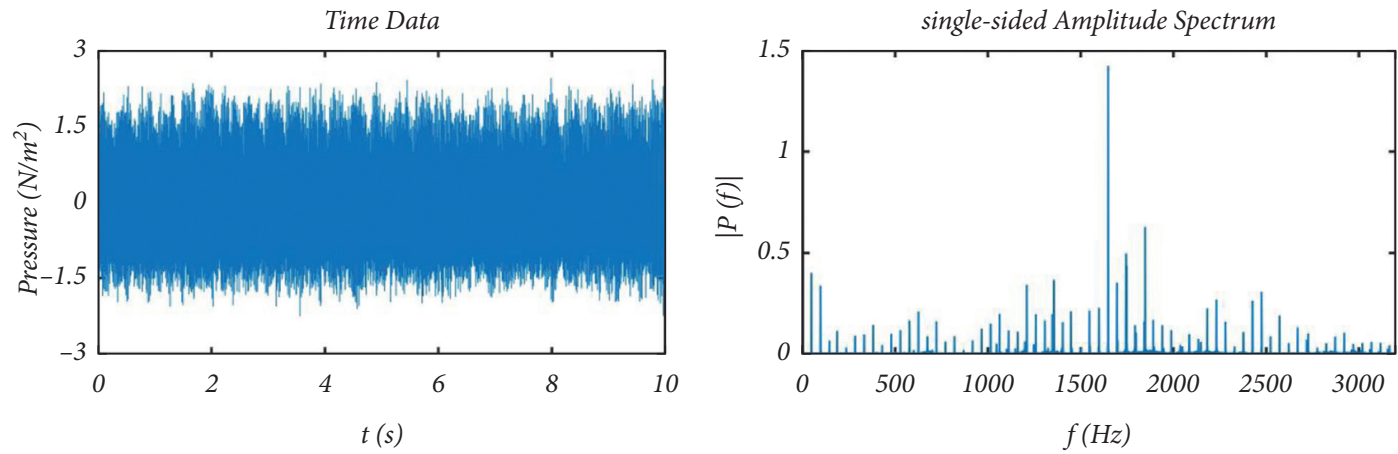

(c)
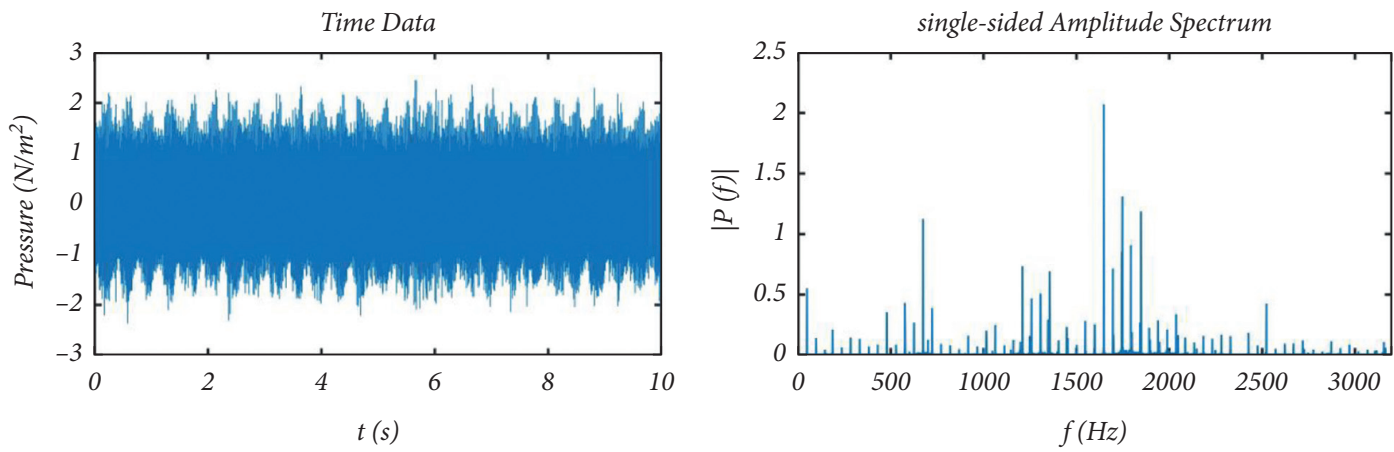

(d)

Figure 20: Time-domain and frequency-domain data for experimental tests. (a) Point 1. (b) Point 4. (c) Point 7. (d) Point 10.
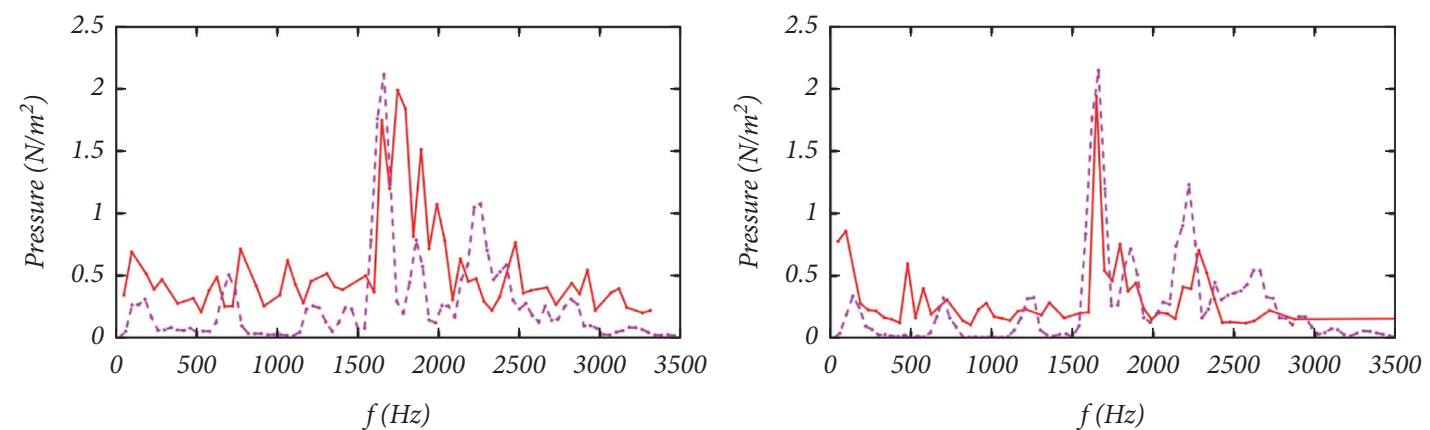

$\rightarrow$ Point.1: test

_.. Point.1: simulation

$\rightarrow$ Point.4: test

-. Point.4: simulation
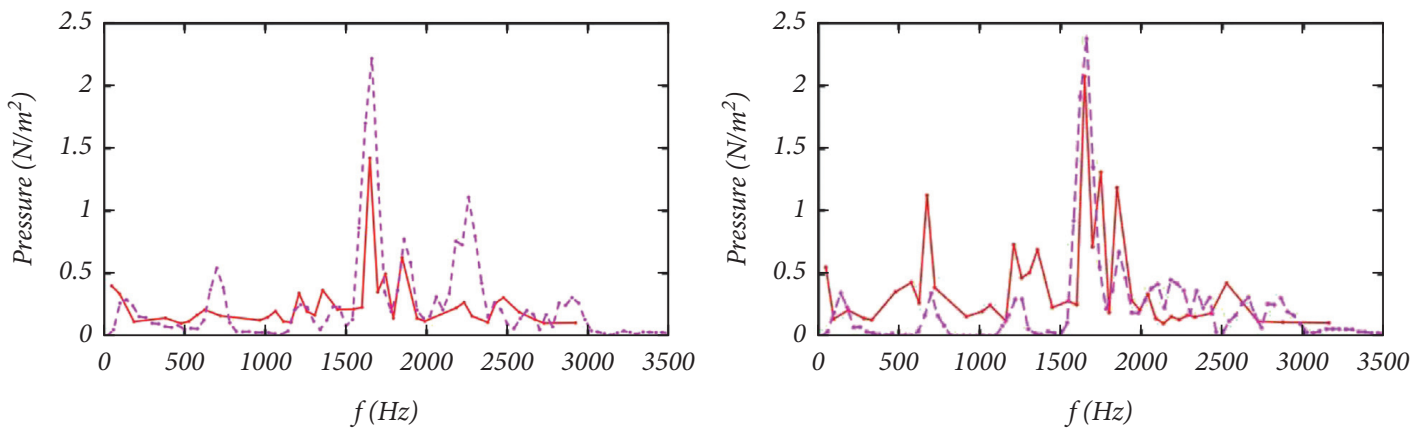

$\rightarrow$ Point.7: test

- - Point.7: simulation

$\rightarrow$ Point.10: test

- - Point.10: simulation

FIgURE 21: Time-domain and frequency-domain data for experimental test. 
composed of housing, upper support, stator sleeve, and lower support, contributes to most of the structural noise, while the peak sound pressure near $1650 \mathrm{~Hz}$ is mainly caused by the first-order bending resonance of the upper support.

6.2. Experimental Comparison and Error Analysis. Points 1, 4,7 , and 10 near the upper support are selected as the research objects, and the spectral characteristics of experiment and simulation are compared. As shown in Figure 21, the main peak points of the spectrum are extracted by signal processing. The comparison shows that the simulation results are consistent with the experimental results, especially at the maximum peak frequency, which ensures the credibility of the simulation results.

The simulation error analysis is demonstrated as follows:

(1) Due to the existence of load and other factors, the working frequency of scroll compressor is often slightly lower than $50 \mathrm{~Hz}$ in the actual working process.

(2) The upper support, stator sleeve, and lower support are coupled with the housing through binding constraints. In practice, interference fit and spot welding are used to realize the connection.

(3) In the multibody dynamics analysis of HSC, the crankshaft, the moving scroll, and the static scroll are all rigid bodies, and the additional load caused by the deformation of the components is ignored.

(4) The calculated gas force is used to replace the actual gas load, and the gas excitation model is simplified.

\section{Conclusions}

In this paper, the dynamic characteristics, vibration response, and housing radiated noise of the HSC are analyzed and discussed in detail. The rationality and accuracy of the model are verified by experiments. The main conclusions are as follows:

(1) The experimental results show that the vibration and radiation noise of the housing can be accurately predicted by reasonable modeling to calculate the gas force and approximate the actual gas load.

(2) Compared with the gas force and noise spectrum characteristics, the vibration of the housing coupling system is the main source of the vibration characteristics of the HSC, and the first-order bending resonance of the upper support is the main reason for the high sound pressure at $1650 \mathrm{~Hz}$.

(3) The upper support, lower support, and housing are the main sources of vibration and radiation noise of the scroll compressor. Their maximum peaks are the same. Special attention should be paid to the reasonable design of these components.

(4) The relevant research methods and analysis process used in this paper can provide reference for dynamic analysis, vibration response, and radiated noise prediction.

\section{Abbreviations}

HSC: High-power scroll compressor

DM: A general term for a class of computing strategies

RE: Reverse engineering

CFD: Computational fluid dynamics

TPA: Transmission path analysis.

\section{Data Availability}

The data used to support the findings of this study are available from the corresponding author upon request.

\section{Conflicts of Interest}

The authors declare that there are no conflicts of interest regarding the publication of this paper.

\section{Acknowledgments}

This work was financially supported by the National Natural Fund Joint Fund of China (U1808214, Flow-Induced Vibration Mechanism and Intelligent Diagnosis of Large Centrifugal Compressor Impeller).

\section{References}

[1] M. Takeuchi, T. Ukai, H. Yamazaki, S. Mishima, T. Moro, and K. Watanabe, "An Environmentally Friendly, Highly Efficient, Lightweight Scroll Compressor (QS90) for Car Air Conditioners," Mitsubishi Heavy Industries, Ltd, Chiyoda, Japan, Technical Review, vol. 45, 2008.

[2] J. P. Elson, N. Kaemmer, S. Wang, and M. Perevozchikov, "Scroll technology: an overview of past, present and future developments," in International Compressor Engineering Conference, Purdue University, Purdue, IN, USA, July 2008.

[3] J. Qiang, B. Peng, and Z. Liu, "Dynamic model for the orbiting scroll based on the pressures in scroll chambers - Part II: i," International Journal of Refrigeration, vol. 36, no. 7, pp. 1850-1865, 2013.

[4] E. Morishita, M. Sugihara, T. Inaba, and T. Nakamura, "Scroll compressor analytical model," in Proceedinfgs of the International Compressor Engineering Conference, Purdue, IN, USA, 1984.

[5] N. Ishii, M. Fuhushima, K. Sano, and K. Sawai, "A study on dynamic behavior of a scroll compressor," in Proceedinfgs of the International Compressor Engineering Conference, Purdue, IN, USA, 1986.

[6] N. Ishii, M. Sakai, M. Yamarnura, H. Morokoshi, M. Fukushima, and S. Yamamoto, "On the superior dynamic behavior of a variable rotating speed scroll compressor," in Proceedinfgs of the International Compressor Engineering Conference, Purdue, IN, USA, 1988.

[7] H. J. Kim, J. Lee, and D. Shin, "Design of phase-angled balance weights for an inverter driven scroll compressor," in Proceedinfgs of the International Compressor Engineering Conference, Purdue, IN, USA, 1998.

[8] S.-H. Lee, S.-M. Ryu, and W.-B. Jeong, "Vibration analysis of compressor piping system with fluid pulsation," Journal of Mechanical Science and Technology, vol. 26, no. 12, pp. 3903-3909, 2012.

[9] M. Morini, C. Pavan, M. Pinelli, E. Romito, and A. Suman, "Analysis of a scroll machine for micro ORC applications by 
means of a RE/CFD methodology," Applied Thermal Engineering, vol. 80, pp. 132-140, 2015.

[10] K. Ye, J. Ji, and S. Han, "Semi-active noise control for a hermetic digital scroll compressor," Journal of Low Frequency Noise, Vibration and Active Control, vol. 39, no. 4, pp. 1204-1215, 2020.

[11] S. Shao, F. Qin, C. Tian, and H. Yang, "Model simplification of scroll compressor with vapor refrigerant injection," International Journal of Green Energy, vol. 13, 2016.

[12] Z. Wang, Z. H. Zhao, C. L. Yang, and X. J. Ma, Study on the Properties of Vibration and Noise for Scroll Compressor, Compressor Technology, Ahmedabad, India, 2005.

[13] K. Tojo, M. Ikegawa, M. Shiibayashi, N. Arai, and A. Arai, A Scroll Compressor for Air Conditioners, Purdue University, Purdue, IN, USA, 1984.

[14] B. Blunier, G. Cirrincione, Y. Hervé, and A. Miraoui, “A new analytical and dynamical model of a scroll compressor with experimental validation," International Journal of Refrigeration, vol. 32, no. 5, pp. 874-891, 2009.

[15] L. I. Chao, Y. U. Yang, and M. Zhao, "Virtual modeling and dynamic simulation of scroll compressor," Fluid Machinery, McGraw-Hill Education, New York, NY, USA, 2012.

[16] D. Su and Z. Wang, "Study on Mechanism Analysis and Motion Simulation of the Scroll Compressor," in Proceedings of the Mechanical Engineering and Control Systems:Proceedings of 2015 International Conference on Mechanical Engineering and Control Systems (MECS2015), Wuhan, China, January 2016.

[17] J. Iizuka, N. Kitano, S. Ito, and S. Otake, "Improvement of scroll compressor for vehicle air conditioning systems," TR 970113, Sae International Congress \& Exposition, Warrendale, PA, USA, 1997.

[18] M. Zhao, C. Li, S. R. Yu, and Y. Yu, "Effect of radial compliance mechanism on rotor system and bearing load for scroll compressor," in Proceedings of the 2nd International Conference on Energy, Environment and Sustainable Development, EESD 2012, vol. 614, pp. 600-603, Advanced Materials Research: Trans Tech Publ, Jilin, China, 2013.

[19] M. Zhao, L. I. Chao, Y. U. Shu-Rong, and Y. Yang, "Radial compliance mechanism effect on rotor balancing system for scroll compressor," Chemical Engineering \& Machinery, vol. 6, 2012.

[20] J. Qiang, B. Peng, and Z. Liu, "Dynamic model for the orbiting scroll based on the pressures in scroll chambers-Part I: analytical modeling," International Journal of Refrigeration, vol. 36, no. 7, pp. 1830-1849, 2013.

[21] L. P. Franzoni, D. B. Bliss, and J. W. Rouse, "An acoustic boundary element method based on energy and intensity variables for prediction of high-frequency broadband sound fields," Journal of the Acoustical Society of America, vol. 110, no. 6, pp. 3071-3080, 2001.

[22] S.-C. Kang and J. G. Ih, "On the accuracy of nearfield pressure predicted by the Acoustic Boundry Element Method," Journal of Sound and Vibration, vol. 233, no. 2, pp. 353-358, 2000.

[23] B. A. Auld and R. E. Green, "Acoustic fields and waves in solids: two volumes," Physics Today, vol. 27, no. 10, pp. 63-64, 1974.

[24] Z. Wang, D. L. Chen, and H. J. Zhao, "Identify for scroll compressor noise using vibration signal based on neural network," Advanced Materials Research, vol. 295-297, pp. 2201-2204, 2011. 